\title{
An IFOC-DSVPWM Based DC-Link Voltage Compensation of Z-Source Inverter Fed Induction Motor Drive for EVs
}

\author{
Ananda Kumar Akkarapaka and Dheerendra Singh \\ Department of Electrical and Electronics Engineering, Birla Institute of Technology and Science, Pilani, Rajasthan 333031, India
}

Correspondence should be addressed to Ananda Kumar Akkarapaka; akkarapaka.ananda@gmail.com

Received 17 March 2015; Revised 15 June 2015; Accepted 16 June 2015

Academic Editor: Don Mahinda Vilathgamuwa

Copyright (C) 2015 A. K. Akkarapaka and D. Singh. This is an open access article distributed under the Creative Commons Attribution License, which permits unrestricted use, distribution, and reproduction in any medium, provided the original work is properly cited.

\begin{abstract}
The drop in DC-link voltage of adjustable speed drives (ASD) occurs mainly due to the increase in output power demands. This may lead to inefficient operation and eventually the tripping of the drive. This paper presents a Double Space Vector Pulse Width Modulation (DSVPWM) technique for boosting and compensating the DC-link voltage of Z-source inverter (ZSI). The DSVPWM technique estimates the required shoot through period of the Z-source inverter to maintain the DC-link voltage constant at the desired level through capacitor voltage control. The DSVPWM can obtain maximum boost at any given modulation index in comparison to simple boost control (SBC) method. It also utilizes the dead time more effectively. The speed control of the ZSI fed induction motor drive is done by employing indirect field-oriented (IFO) control method. A 32-bit DSP (TMS320F28335) is used to implement the IFOC-DSVPWM method for ZSI. The power structure and the modulation technique are well suited for electric vehicle application.
\end{abstract}

\section{Introduction}

Why electric vehicles? The world population and vehicles are increasing rapidly. In the next 100 years, the growth of the world population will be from 7 to 15 billion and the number of vehicles may increase from 0.7 to 3 billion. If all these vehicles are propelled by internal combustion engines (ICEs), where will the oil come from? Where should the emissions be accommodated? The need of the hour is emission-free road transportation for the 21st century.

In the world where environmental protection and energy conservation are growing concerns, the development of EV technology will achieve these demands. The EVs can provide emission-free urban transportation. In the energy aspect, EVs can offer a secure and balanced energy from various kinds of the renewable energies. Therefore, EVs will have a great impact on energy, environment, transportation, new industry creation, and economic development $[1,2]$.

The main components of the EV are (i) battery as an electrical energy source, (ii) a power converter which controls electrical energy, (iii) an electrical motor as an electromechanical conversion device for traction, and (iv) a central
DSP or microcontroller as a control system for the power converter. Selection of electrical (traction) motors for propulsion systems is a very important step that requires special attention. In fact, the automotive industry is still seeking for the most appropriate electric propulsion system for EV. In this case, key issues are efficiency, torque density, weight, cost, cooling, maximum speed, fault-tolerance, safety, and reliability. The types of electric motors adapted for electric vehicles are DC motor, the induction motor, the permanent magnet synchronous motor, and the switched reluctance motor. Of late, the cage induction motors are accepted as the most suitable motors for the electric propulsion of EVs owing to their reliability, ruggedness, low maintenance, low cost, and ability to operate in inimical environments. They are particularly well suited for industrial and traction drive environments. Today, induction motor drive is the most mature technology among various commutatorless motor drives. The high performance control of induction motors can decouple its torque and field control $[3,4]$.

In a voltage source inverter fed induction motor for an $\mathrm{EV}$, the speed control techniques are scalar control $(V / F)$, indirect field-oriented control (IFOC), and direct torque 
control (DTC). For low price applications, the volts per hertz induction motor drives with voltage source inverters are widely used in industry. The main advantage of the $V / F$ control is its simplicity, but its accuracy is low and its torque response is poor. For those applications which require better dynamic performance, the indirect field-oriented control (IFOC) or the direct torque control is preferred. These methods have several common aspects, such as the decoupled control of motor flux and torque, fast torque response, and sensitivity to certain motor parameters. The flux command in conventional IFOC is the direct-axis rotor flux in the synchronous frame, while that of DTC is the stator flux in the synchronous frame. IFOC avoids the need for a flux estimator. References [5-7] conclude that IFOC-SVPWM performs well comparable to the DTC-SVPWM.

The electric drive employs a DC-DC boost converter for boosting the low voltage of a battery for the DC-AC inverter. The problem in adding a boost converter is that it increases the cost and lowers the efficiency and reliability of the system. When the load on a drive is suddenly increased, the DC-bus voltage experiences drop. This voltage drop can be so much to an extent that it could lead to a loss of power delivery to the load. So, this voltage drop has to be compensated for better reliability. In addition to this, the dead time with which the inverter is operated to ensure safety distorts the output voltage waveform. A combined solution for voltage drop compensation and minimization of output voltage distortion is impedance or Z-source inverter. This will be dealt with in detail in a subsequent section. A Z-source inverter has a Znetwork between the DC electrical source and the inverter. The capacitor voltage of the Z-network acts as a DC-link for the inverter. ZSI intentionally avoids the dead time and creates a shoot-through to boost the capacitor voltage in the Z-network which in turn compensates the voltage drop.

The proposed DSVPWM method can achieve the maximum boost at any given modulation index and with better DC-link voltage utilization is achieved compared to SBC method. The organization of the paper is as follows. Section 2 describes the small signal analysis and components design of the Z-source inverter. Section 3 describes the DSVPWM boost technique. Section 4 describes the DC-link voltage control through capacitor control. Section 5 describes speed control of induction motor. Section 6 inculcates hardware implementation of VSI and ZSI drive, the results discussion.

\section{Z-Source Inverter}

The operational problems associated with voltage source and current source inverters led to the development of $\mathrm{Z}$ source inverter. As shown in Figure 1, a Z-network is inserted between DC source and 3 legs of inverter switches. The DC source can be battery, diode rectifier, fuel cell, and so forth. The apparent features of Z-source system are as follows [8].

(i) Z-network is a second-order filter, which is more effective in suppressing voltage ripples than capacitor filter used in the traditional PWM inverters.

(ii) The inductor limits the in-rush current and current harmonics.

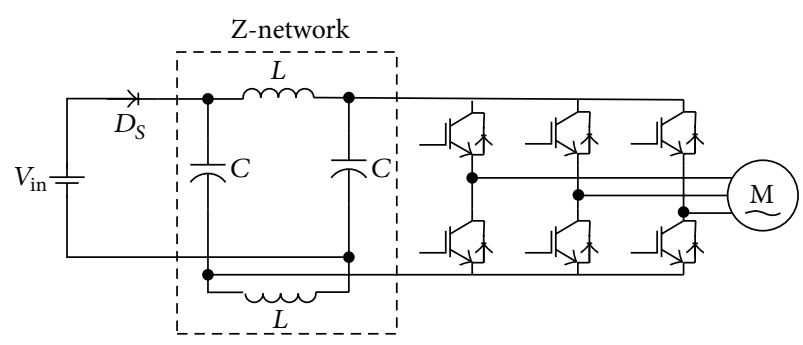

FIGURE 1: Schematic of a Z-source inverter fed induction motor.

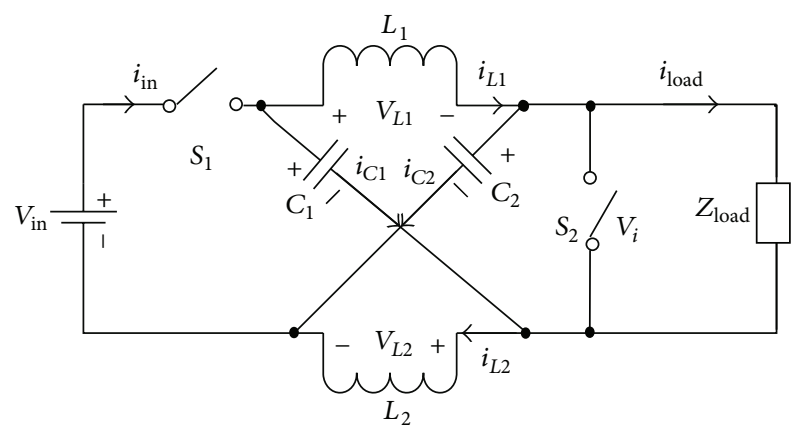

FIGURE 2: Simplified equivalent circuit of the ZSI.

(iii) Z-network provides boosting in voltage across the DC-link.

(iv) The shoot-through state facilitates boosting in output voltage, instead of damage to the power circuit.

2.1. Small Signal Model. In view of complete understanding of dynamic response of the system, it is necessary to have state space averaged small-signal model of the converter.

The ZSI equivalent circuit is shown in Figure 2. The small signal modeling begins with the following assumptions: (i) the passive components in the Z-network are lossless; (ii) the load current is continuous; and (iii) the input voltage $V_{\text {in }}$ is an independent voltage source. The capacitor voltage $V_{c}$, the inductor current $I_{L}$, and the load current $I_{\text {Load }}$ are the state variables and they operate in two modes $[9,10]$.

Mode 1. Inverter circuit as shown in Figure 3(a) is operating in one of the six active states and the circuit can be seen as an equivalent current source. During this mode, the DC source voltage appears across the inductor and the capacitor. The power transfers from the source to the load through inductor.

Mode 2. Inverter circuit as shown in Figure 3(b) is operating in one of the seven different ways of shoot-through state. The inverter circuit looks like a "short circuit" from the DC-link of the inverter and in shoot-through state, the capacitor voltage becomes higher than the input DC voltage, which makes the diode $D_{s}$ reverse-biased. The voltage does not appear across the load like in the zero state.

During this mode, there is no power transfer from the source to the load because the load and source sides are decoupled by the shoot-through state and the open switch $S_{1}$. 


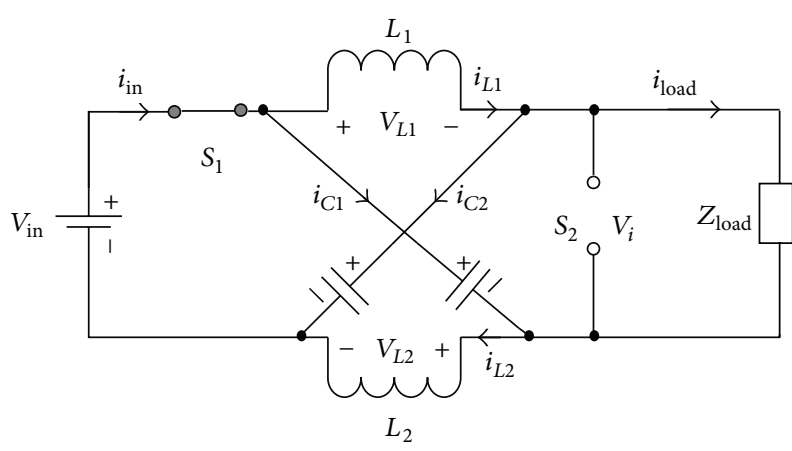

(a)

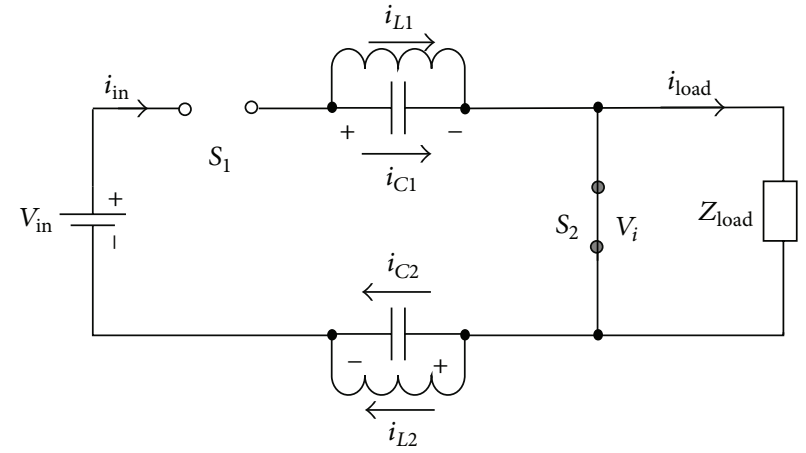

(b)

FIGURE 3: Equivalent circuit for different modes of operation: (a) non-shoot-through state and (b) shoot-through state.

The standard state space equations are written in matrix form using state space averaging method and performing small signal perturbation for a given operating point [11-14] (linearising the system) as follows:

Z-network inductor $L_{1}=L_{2}=L$ and capacitor $C_{1}=$ $C_{2}=C$,

$$
\begin{aligned}
& \frac{d}{d t}\left[\begin{array}{c}
\tilde{i}_{L}(t) \\
\tilde{v}_{C}(t) \\
\tilde{i}_{\text {Load }}(t)
\end{array}\right] \\
& =\left[\begin{array}{ccc}
0 & \frac{2 D_{\text {sh }}-1}{L} & 0 \\
\frac{1-2 D_{\text {sh }}}{C} & 0 & \frac{-\left(1-D_{\text {sh }}\right)}{C} \\
0 & \frac{2\left(1-D_{\text {sh }}\right)}{L_{\text {Load }}} & \frac{-R_{\text {Load }}}{L_{\text {Load }}}
\end{array}\right] \\
& \text { * }\left[\begin{array}{c}
\tilde{i}_{L}(t) \\
\tilde{v}_{C}(t) \\
\tilde{i}_{\text {Load }}(t)
\end{array}\right]+\left[\begin{array}{c}
\frac{1-D_{\text {sh }}}{L} \\
0 \\
\frac{-\left(1-D_{\text {sh }}\right)}{L_{\text {Load }}}
\end{array}\right] \widetilde{v}_{\text {in }}(t) \\
& +\left[\begin{array}{c}
\frac{2 V_{c}-V_{\text {in }}}{L} \\
\frac{2 I_{L}+I_{\text {Load }}}{C} \\
\frac{2 V_{c}+V_{\text {in }}}{L_{\text {Load }}}
\end{array}\right] .
\end{aligned}
$$

From Laplace transformation of (1),

$$
\begin{aligned}
s L \tilde{i}_{L}(s)= & \left(2 D_{\text {sh }}-1\right) \widetilde{v}_{c}(s)+\left(1-D_{\text {sh }}\right) \widetilde{v}_{\text {in }}(s) \\
& +\left(2 V_{c}-V_{\text {in }}\right) \widetilde{d}_{\text {sh }}(s) \\
s L \widetilde{v}_{c}(s)= & \left(1-2 D_{\text {sh }}\right) \tilde{i}_{L}(s)-\left(1-D_{\text {sh }}\right) \tilde{i}_{\text {Load }}(s) \\
& +\left(-2 I_{L}+I_{\text {Load }}\right) \widetilde{d}_{\text {sh }}(s)
\end{aligned}
$$

$$
\begin{aligned}
s L \widetilde{i}_{\text {Load }}(s)= & 2\left(1-D_{\text {sh }}\right) \widetilde{v}_{c}(s)-R_{\text {Load }} \tilde{i}_{\text {Load }}(s) \\
& -\left(1-D_{\text {sh }}\right) \widetilde{v}_{\text {in }}(s) \\
& +\left(-2 V_{c}+V_{\text {in }}\right) \widetilde{d}_{\text {sh }}(s) .
\end{aligned}
$$

Use the following relationships for the capacitor voltage and inductor current [15]:

$$
\begin{aligned}
V_{c} & =\frac{1-D_{\text {sh }}}{1-2 D_{\text {sh }}} V_{\text {in }} \\
I_{L} & =\frac{1-D_{\text {sh }}}{1-2 D_{\text {sh }}} I_{\text {Load }} \\
I_{\text {Load }} & =\frac{V_{c}}{R_{\text {Load }}} .
\end{aligned}
$$

The DC-link voltage is pulsating due to shoot-through state. The DC-link voltage peak value during the non-shootthrough state is $v_{\mathrm{dp}}=2 v_{c}-v_{\mathrm{in}}$ and during shoot-through state is zero. Therefore, the perturbation in the DC-link voltage has been written as

$$
\widetilde{v}_{\mathrm{dp}}=2 \widetilde{v}_{c}-\widetilde{v}_{\text {in }} .
$$

From small single modeling, the capacitor voltage, the inductor current, and the DC-link voltage can be expressed as a linear combination of the variable response to each individual perturbation as

$$
\begin{gathered}
\widetilde{v}_{c}(s)=G_{v d}(s) \widetilde{d}_{\mathrm{sh}}+G_{v i}(s) \widetilde{v}_{\mathrm{in}} \\
\widetilde{i}_{L}(s)=G_{i d}(s) \widetilde{d}_{\mathrm{sh}}+G_{i i}(s) \widetilde{v}_{\mathrm{in}} \\
\widetilde{v}_{\mathrm{dp}}(s)=G_{\mathrm{dpd}}(s) \widetilde{d}_{\mathrm{sh}}+G_{\mathrm{dp} v}(s) \widetilde{v}_{\mathrm{in}},
\end{gathered}
$$

where $G_{v d}(s), G_{v i}(s), G_{i d}, G_{i i}, G_{\mathrm{dpd}}$, and $G_{\mathrm{dp} v}$ are individual transfer functions.

\subsection{Z-Network Components Design}

Mode 1. During non-shoot-through condition, inductor voltage is different from capacitor voltage and inductor current decreases linearly. 
Mode 2. Capacitor and inductor voltage become equal and inductor current increases linearly [16].

So the average current through inductor can be written as

$$
\bar{I}_{L}=\frac{P}{V_{\text {in }}},
$$

where $P$ is converter power rating and $V_{\text {in }}$ is input DC source voltage.

When the shoot-through period is maximum, the current ripple through the inductors becomes maximum. For the design of inductor, inductor current ripple is considered as $50 \%$ of the inductor current:

Max. inductor current $\widehat{I}_{L}=\bar{I}_{L}+30 \% I_{L}$;

Min. inductor current $\check{I}_{L}=\bar{I}_{L}-30 \% I_{L}$.

In ZSI [15],

$$
\begin{aligned}
& V_{\mathrm{dp}}=B V_{\mathrm{in}} \\
& V_{\mathrm{dp}}=2 V_{c}-V_{\mathrm{in}} \\
& D_{\mathrm{sh}}=\frac{T_{\mathrm{sh}}}{T}=\frac{B-1}{2 B} .
\end{aligned}
$$
cycle.

$T=1 / f_{s} ; T_{\text {sh }}$ is the shoot-through period per switching

From (7), (8), and (9), capacitor voltage $V_{c}$ can be expressed as

$$
V_{c}=\frac{(B+1) V_{\mathrm{in}}}{2}
$$

or

$$
V_{c}=\frac{1-\left(T_{\mathrm{sh}} / T\right)}{1-\left(2 T_{\mathrm{sh}} / T\right)} V_{\mathrm{in}}
$$

During shoot-through, $V_{L}=V_{C}=V$.

Inductor value is

$$
L=\frac{V * T_{\mathrm{sh}}}{\Delta I},
$$

where $\Delta I=\widehat{I}_{L}-\check{I}_{L}$.

Restricting the capacitor voltage ripple $\left(\Delta V_{c}\right)$ to less than $1 \%$, the capacitor value can be calculated as

$$
C=\frac{\bar{I}_{L} T_{\mathrm{sh}}}{\Delta V_{c}} .
$$

The designed/calculated values of Z-network are given in the appendix.

\section{PWM Technique}

In inverters, there are many PWM techniques in use. Sinusoidal Pulse Width Modulation (SPWM) technique is the most basic technique in practical applications. The Space Vector Pulse Width Modulation (SVPWM) is an advanced computation-intensive PWM technique, preferred in realtime realization, being widely used in voltage source inverters. This technique generates reference three-phase signals by sharing the space vector among the active and zero vectors such that the harmonic content is optimized. The maximum inverter line-to-line voltage generated by the SVPWM scheme is $15.5 \%$ higher than that of the SPWM for a given DC bus voltage $[17,18]$.

In SVPWM technique for VSI, eight switching states (six active + two zero/null) are realised. During the six active states, the supply is connected to the load and during the two zero/null states, the load terminals are shortened by the switching devices. In the ZSI, an extra state called shootthrough state is realised during which upper and lower switching devices of the same leg are turned on [19]. This state is forbidden in traditional VSI as it leads to supply short circuit and results in high and device-damaging surge current. In ZSI, the advantage of having Z-network between the supply and the inverter switches is that the rise in the shoot-through state current is limited by the inductor of the Z-network. In addition to this, the inductor in Z-network stores energy during this state to boost the capacitor voltage and helps in regulating it. This shoot-through state sometimes also called the third zero state is generated in seven different ways: shoot-through via any phase, combinations of any two-phase legs, and all three-phase legs. Its duration can be adjusted/controlled for different output voltage gain by different boost control methods.

In the Simple Boost Control (SBC) method [15], the resulting voltage stress across the switches is higher as some portion of traditional zero states is not utilized. The Double Space Vector Pulse Width Modulation (DSVPWM) technique uses two sets of three-phase signals as reference signals and a high frequency triangular wave as carrier signal [20]. Let $V_{a 1}, V_{b 1}$, and $V_{c 1}$ be the first set of reference signals generated by SVPWM technique for required modulation " $m$ " of input voltage. Let $V_{a 2}, V_{b 2}$, and $V_{c 2}$ be the second set of reference signals generated by adding a finite negative DC offset $\left(V_{\text {offset }}\right)$ to the first set. The reference signals $V_{a 1}$ and $V_{a 2}$ will generate pulse for top switch and bottom switch of leg " $a$," respectively, as shown in Figure 4. The offset results in a shoot-through time $T_{\text {sha }}$ per switching period in that leg. For high switching frequencies, the reference signals $V_{a 1}$ and $V_{a 2}$ can be approximated as constant during a switching cycle. The relation between the shoot-through time $T_{\text {sha }}$ and $V_{\text {offset }}$ can be established as follows: In Figure 5, consider similar triangles " $x y z$ " and " $X Y Z$ ":

$$
\begin{aligned}
x y & =\left(\frac{y z}{Y Z}\right) * X Y \\
\frac{T_{\text {sha }}}{2} & =\left(\frac{V_{\text {offset }}}{1-(-1)}\right) *\left(\frac{T}{2}\right) .
\end{aligned}
$$

Shoot-through time of leg $a$ is

$$
T_{\text {sha }}=\left(V_{\text {offset }}\right) *\left(\frac{T}{2}\right) .
$$




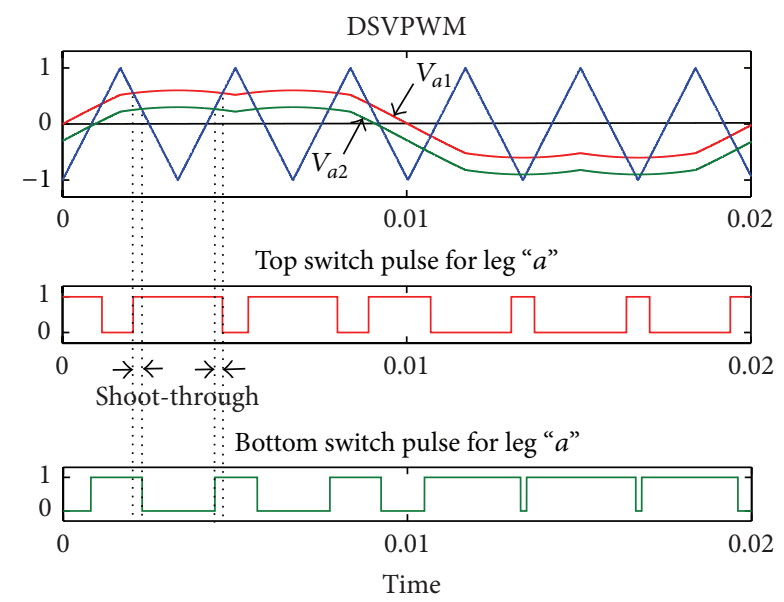

FIGURE 4: DSVPWM pulses for phase $a$.

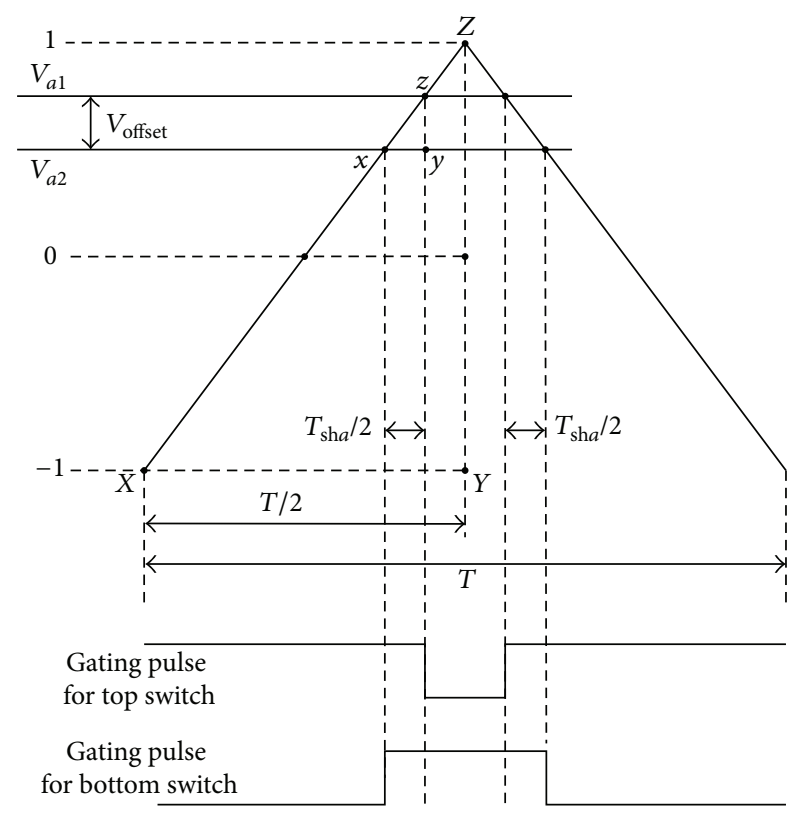

FIGURE 5: Generating DSVPWM shoot-through in leg $a$ of inverter.

The shoot-through time in all three legs of the inverter remains the same whereas the instants at which they occur during a switching period vary. So, the shoot-through time in legs $b$ and $c$ is

$$
T_{\mathrm{sh} b}=T_{\mathrm{sh} c}=T_{\mathrm{sh} a}=\left(V_{\mathrm{offset}}\right) *\left(\frac{T}{2}\right)
$$

The total shoot-through time $T_{\text {sh }}$ per switching period can be written as

$$
T_{\mathrm{sh}}=3 * T_{\mathrm{sh} a}=3 *\left(V_{\mathrm{offset}}\right) *\left(\frac{T}{2}\right)
$$

The shoot-through duty ratio $D_{\text {sh }}$ can be defined as

$$
\begin{aligned}
D_{\text {sh }} & =\frac{\text { shoot-through time }\left(T_{\mathrm{sh}}\right)}{\text { total switching time }(T)} \\
D_{\text {sh }} & =3 * \frac{V_{\text {offset }}}{2} \\
V_{\text {offset }} & =2 * \frac{D_{\text {sh }}}{3} .
\end{aligned}
$$

The DSVPWM technique introduces $V_{\text {offset }}$ to extend the pulse width of the bottom switch into the top switch pulse width to result in shoot-through time. When the ZSI is operated at a SVPWM modulation index of " $m$," the minimum pulse-width of the top switch is $(1-m) * T / 2$ and it occurs in a switching period during the negative half-cycle of the fundamental wave. The bottom switch pulse width during this switching period is $(1+m) * T / 2$ when $V_{\text {offset }}$ is zero. As $V_{\text {offset }}$ increases, the bottom switch pulse width increases from $(1+m) * T / 2$ to a maximum of $T$ at a maximum offset voltage $V_{\text {offset_max }}$. On further increase in $V_{\text {offset }}$, SVPWM operation enters overmodulation region. So, the maximum limit $V_{\text {offset_max }}$ can be obtained as follows.

At maximum offset voltage $V_{\text {offset_max }}$ condition, if $T_{\text {sha_max }}$ is the maximum shoot-through time of leg $a$,

$$
\begin{aligned}
& T_{\text {sha_max }}=T-(1+m) * \frac{T}{2} \\
& T_{\text {sha_max }}=(1-m) * \frac{T}{2} .
\end{aligned}
$$

From (15),

$$
T_{\text {sha_max }}=\left(V_{\text {offset_max }}\right) * \frac{T}{2} .
$$

Substituting in (22),

$$
\begin{aligned}
\left(V_{\text {offset_max }}\right) * \frac{T}{2} & =(1-m) * \frac{T}{2} \\
V_{\text {offset_max }} & =1-m .
\end{aligned}
$$

From (19) and (25), the maximum shoot-through duty ratio $D_{\text {sh_max }}$ is

$$
D_{\text {sh_max }}=3 * \frac{(1-m)}{2} .
$$

From (9) and (26), the maximum boost factor $B_{\max }$ is

$$
B_{\max }=\frac{1}{3 m-2}
$$

For SBC control method, the maximum boosting factor that can be obtained is

$$
B_{\text {max_SBC }}=\frac{1}{2 m-1} .
$$

A comparison among SBC and DSVPWM boost control methods for maximum boosting factor $B_{\max }$ variation with 


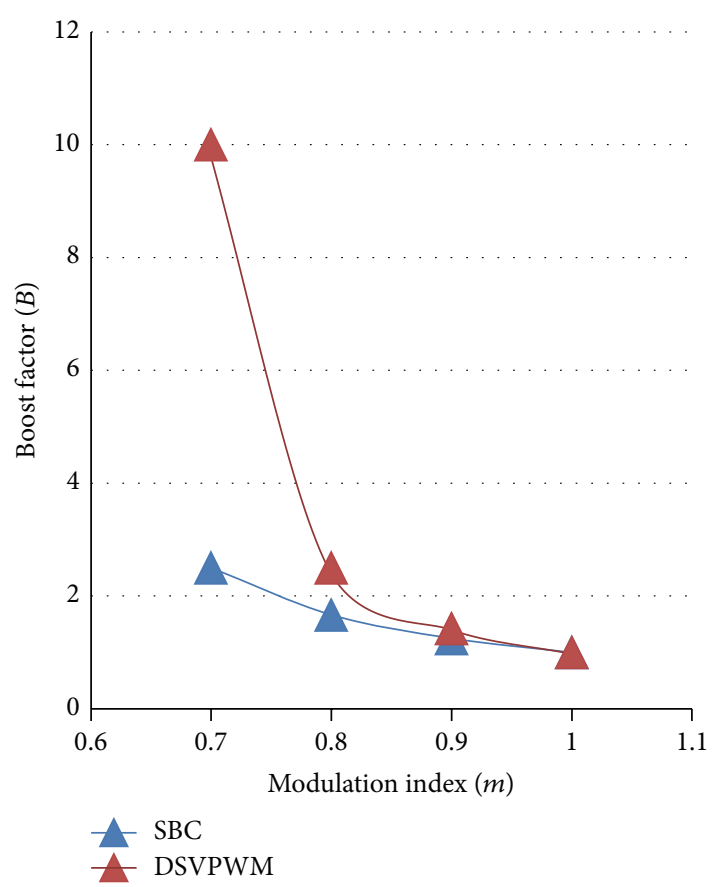

Figure 6: Comparison between control methods.

modulation index $m$ using (27) and (28) is shown in Figure 6. The advantage of DSVPWM technique is that the maximum boosting factor is higher than that of SBC boost control method.

The overall voltage gain of the ZSI using DSVPWM is given as

$$
\frac{\widehat{V}_{\mathrm{Ph} 1}}{V_{\mathrm{in}}}=\frac{2}{3} m * B,
$$

where $\widehat{V}_{\mathrm{Ph} 1}$ is the peak of the fundamental component of phase voltage and $V_{\text {in }}$ is the input DC source voltage.

Modulation index " $m$ " of SVPWM technique is defined as

$$
m=\frac{\widehat{V}_{\mathrm{Ph} 1}}{V_{\mathrm{dp}}} .
$$

Substituting Z-network boost factor $B$ definition from (9) and shoot-through duty ratio $D_{\text {sh }}$ from (18) in (29), we get

$$
\frac{\widehat{V}_{\mathrm{Ph} 1}}{V_{\mathrm{in}}}=\frac{2}{3} m * \frac{1-D_{\mathrm{sh}}}{1-2 * D_{\mathrm{sh}}} .
$$

Table 1 and Figure 7 show variation in the capacitor voltage with the shoot-through time " $T_{\mathrm{sh}}$ " and modulation index " $m$ " for the input voltage $V_{\text {in }}$ of $50 \mathrm{~V}$ and switching frequency $f_{s}$ of $10 \mathrm{kHz}$.

\section{DC-Link Voltage Control}

The DC-link voltage control is worked out for a ZSI fed induction motor drive realizing IFOC along with DSVPWM
TABLE 1: DSVPWM control algorithm observations.

\begin{tabular}{lccc}
\hline & \multicolumn{3}{c}{ Input voltage $\left(V_{\text {in }}\right)=50 \mathrm{~V}$} \\
$\begin{array}{l}\text { Modulation } \\
\text { index }(m)\end{array}$ & $V_{\text {DCoffset }}$ & ST time $\left(T_{\text {sh }}\right)$ & Capacitor voltage $\left(V_{C}\right)$ \\
\hline 0.9 & 0.1 & $15 \mu \mathrm{s}$ & $60.5 \mathrm{~V}$ \\
0.8 & 0.2 & $30 \mu \mathrm{s}$ & $87.5 \mathrm{~V}$ \\
0.7 & 0.3 & $45 \mu \mathrm{s}$ & $275 \mathrm{~V}$ \\
\hline
\end{tabular}

TABLE 2: ZSI parameters.

\begin{tabular}{lc}
\hline Parameters & Value \\
\hline Input voltage $V_{\mathrm{in}}$ & $400 \mathrm{~V}$ \\
DC-link voltage $V_{\mathrm{dp}}$ & $600 \mathrm{~V}$ \\
Z-network capacitor $C_{1}=C_{2}$ & $1000 \mu \mathrm{F}$ \\
Z-network inductor $L_{1}=L_{2}$ & $2 \mathrm{mH}$ \\
Switching frequency $f_{s}$ & $10000 \mathrm{~Hz}$ \\
\hline
\end{tabular}

technique for the required voltage compensation. A change in load or speed effects the DC-link voltage. It is a pulsating value and its control is difficult. So, the DC-link voltage is indirectly controlled by employing the capacitor voltage control. The capacitor voltage control block diagram is shown in Figure 8. The reference capacitor voltage $V_{\text {Cref }}$ is obtained from the reference DC-link voltage $V_{\text {dpref }}$ and input voltage $V_{\text {in }}$ using (4). The error in actual and reference capacitor voltage is fed to a PI controller $G_{c}(s)$ to obtain the appropriate $V_{\text {off set }}$ value. This $V_{\text {offset }}$ value is used to generate the two sets of reference signals as mentioned in DSVPWM technique. The gating pulses obtained from the DSVPWM technique result in both required modulation index $m$ and shoot-through duty ratio $D_{\text {sh }}$. The shoot-through duty ratio calculator uses (19) to calculate $D_{\text {sh }}$ from the $V_{\text {offset }}$ value obtained from the PI controller. It is necessary to establish capacitor voltage $V_{c}(s)$ to shoot-through duty ratio $D_{\text {sh }}(s)$ plant transfer function $G_{v d}(s)$ to tune the PI controller $G_{c}(s)$ for total voltage drop compensation.

The capacitor voltage-to-shoot-through duty ratio plant transfer function $G_{v d}(s)$ is expressed as follows [9]:

$$
G_{v d}(S)=\frac{P_{1} S^{2}+Q_{1} S+R_{1}}{W_{1} S^{3}+X_{1} S^{2}+Y_{1} S+Z_{1}},
$$

where $P_{1}=\left(-2 I_{L}+I_{\text {Load }}\right) L_{L} L, Q_{1}=\left(-2 I_{L}+I_{\text {Load }}\right) R_{\text {Load }} L+(1-$ $\left.D_{\text {sh }}\right)\left(2 V_{C}-V_{\text {in }}\right) L_{\text {Load }}, R_{1}=\left(1-D_{\text {sh }}\right)\left(2 V_{C}-V_{\text {in }}\right) R_{\text {Load }}, W_{1}=$ $L_{\text {Load }} L C, X_{1}=R_{\text {Load }} L C, Y_{1}=2 L\left(1-D_{\text {sh }}\right)^{2}+L_{\text {Load }}\left(2 D_{\text {sh }}-1\right)^{2}$, and $Z_{2}=R_{\text {Load }}\left(2 D_{\text {sh }}-1\right)^{2}$.

Using ZSI parameters in Table 2, induction motor parameters in Table 3, and the closed loop system involving $G_{c}(s)$, $D_{\text {sh }}$ calculator, and transfer function $G_{v d}(s)$, the PI controller $G_{c}(s)$ is tuned. The SISO tool MATLAB/Simulink is used for tuning and the settings of the PI are as follows:

(i) overshoot less than $10 \%$;

(ii) rise time less than 0.01 seconds;

(iii) settling time less than 0.05 seconds;

(iv) steady-state error less than $1 \%$. 


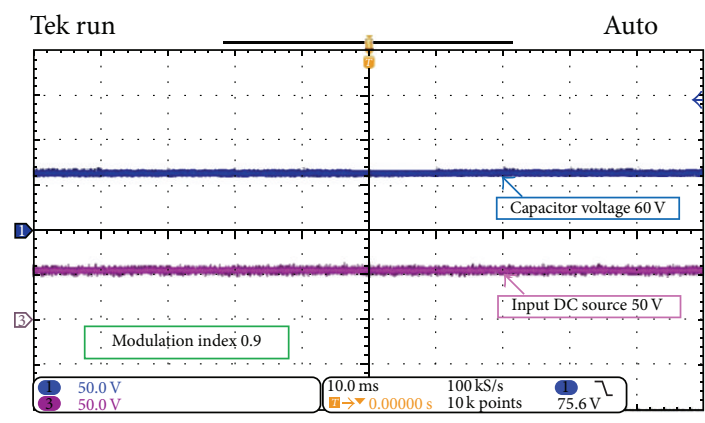

(a)

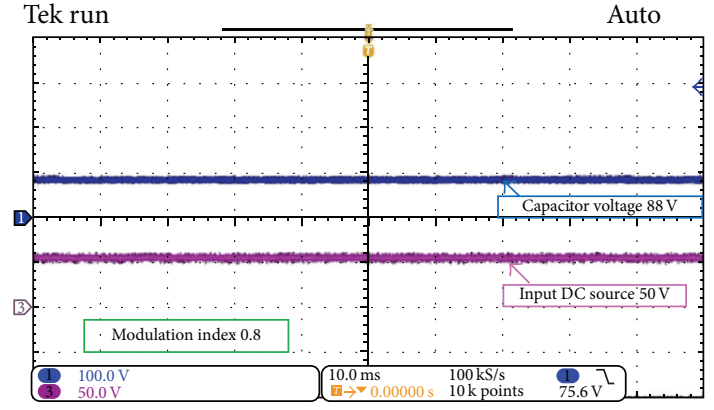

(b)

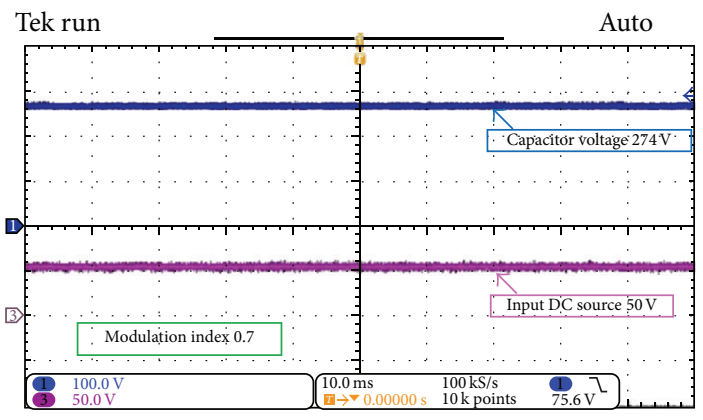

(c)

FIGURE 7: Response of capacitor voltage with different modulation index " $m$."

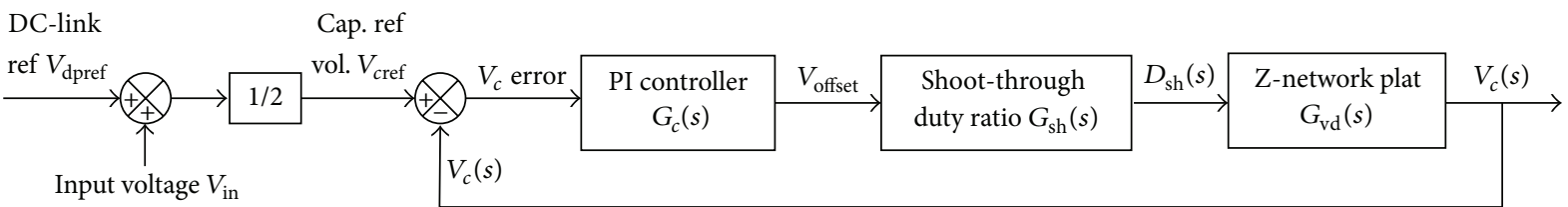

FIGURE 8: Block diagram for capacitor voltage control.

TABLE 3: Induction motor parameters.

\begin{tabular}{lc}
\hline Parameters & Value \\
\hline Output power & $3.2 \mathrm{~kW}$ \\
Line voltage & $400 \mathrm{~V}$ \\
Frequency & $50 \mathrm{~Hz}$ \\
Number of poles $P$ & 4 \\
Speed & $1440 \mathrm{r} . \mathrm{p} . \mathrm{m}$ \\
Stator resistance, $R_{s}$ & $2.125 \mathrm{Ohm}$ \\
Rotor resistance, $R_{r}$ & $2.05 \mathrm{Ohm}$ \\
Stator inductance, $L_{s}$ & $2 \mathrm{mH}$ \\
Rotor inductance, $L_{r}$ & $2 \mathrm{mH}$ \\
Mutual inductance, $L_{m}$ & $6.4 \mathrm{mH}$ \\
Inertia, $J$ & $0.015 \mathrm{~kg} \cdot \mathrm{m}^{2}$ \\
\hline
\end{tabular}

The tuned PI controller exhibits a phase margin (PM) and gain margin (GM) of $59.5 \mathrm{deg}$ and $12.3 \mathrm{~dB}$, respectively. This assures the system stability of the designed mathematical model with the above-mentioned circuit parameters.

The values of the tuned PI controller $G_{c}(s)$ are $K_{p}=$ 0.0075 and $K_{i}=0.095$.

\section{Speed Control}

5.1. Field-Oriented Control. The vector control scheme facilitates an independent control of torque and flux in the induction motor. In this work, rotor flux-oriented scheme has been implemented.

The induction motor in an arbitrary reference frame is expressed by the following equation [21]:

$$
\begin{aligned}
\dot{\psi}_{d r} & =\frac{R_{r}}{L_{r}} i_{d s}-\frac{L_{m} R_{r}}{L_{r}} \psi_{d r}-\left(\omega_{r}-\omega_{a}\right) \psi_{q r} \\
\dot{\psi}_{q r} & =\frac{R_{r}}{L_{r}} i_{q s}-\frac{L_{m} R_{r}}{L_{r}} \psi_{q r}+\left(\omega_{r}-\omega_{a}\right) \psi_{d r} \\
T_{E} & =\frac{3}{2}\left(\frac{P}{2}\right) \frac{L_{m}}{L_{r}}\left(\psi_{d r} i_{q s}-\psi_{q r} i_{d s}\right) \\
\dot{\omega}_{r} & =\frac{P}{2 J}\left(T_{E}-T_{L}\right),
\end{aligned}
$$

where $i_{d s}$ and $i_{q s}$ are the stator $d$ and $q$ currents; $\psi_{d r}$ and $\psi_{q r}$ are the rotor fluxes; $\omega_{r}$ is the rotor angular velocity; $\omega_{a}$ is the angular speed of the arbitrary reference frame; $L_{r}$ and $L_{m}$ are 


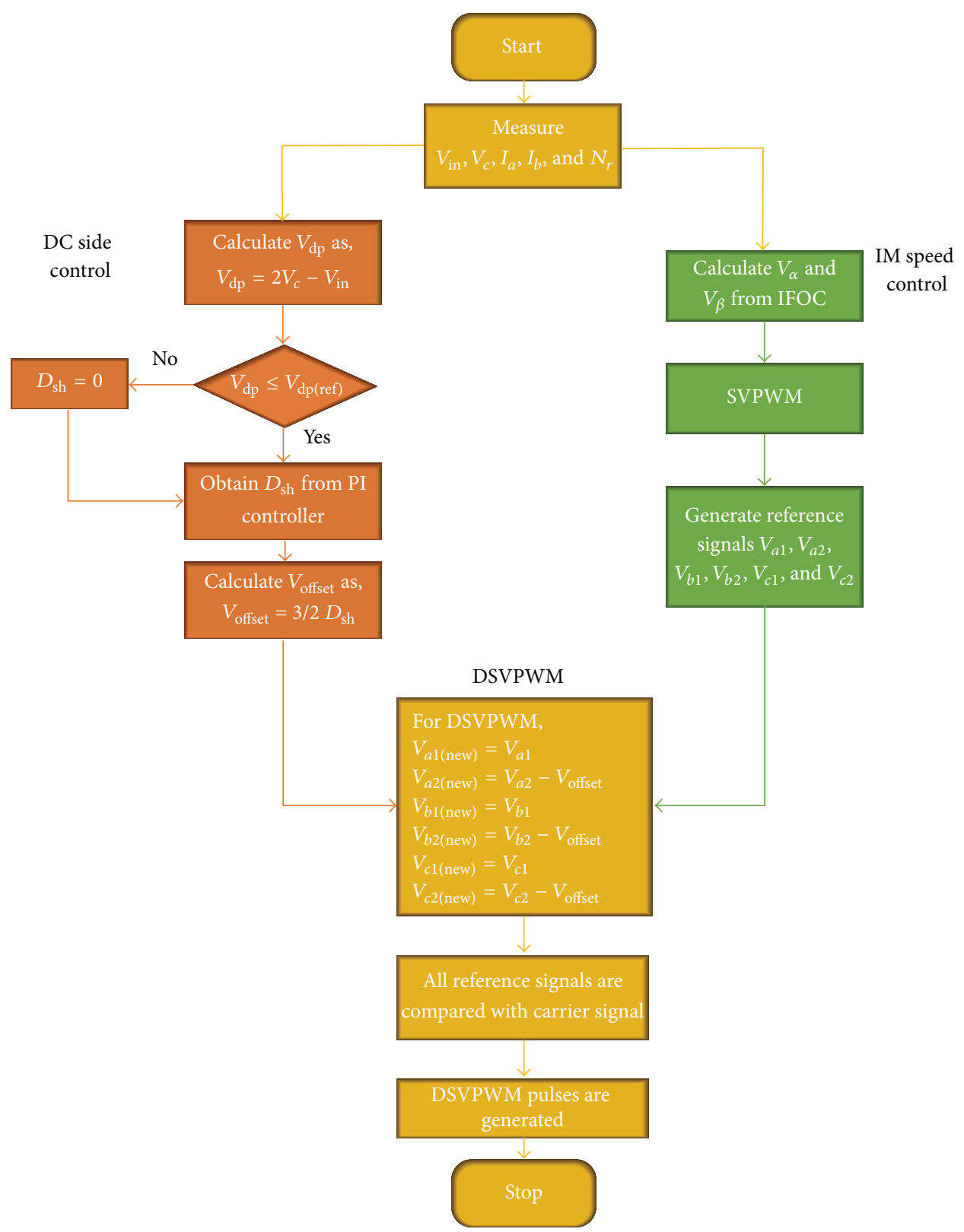

FIGURE 9: Flowchart of IFOC-DSVPWM.

the rotor and mutual inductances, respectively; $R_{r}$ is the rotor resistance; $J$ is the rotor inertia; $T_{L}$ is an external torque load; $P$ is the number of poles; and $T_{E}$ is the generated torque.

\section{Hardware Implementation}

This section explains the hardware implementation of the ZSI fed induction motor drive for voltage drop control. The drive is controlled by programming IFOC algorithm with DSVPWM technique on a TMS320F28335 Texas Instruments Microcontroller. The basic technique of a IFO speed control is that the measured $i_{a}$ and $i_{b}$ line currents are converted into a complex sparse vector $\alpha \beta$-system by Clarke transformation. The space vector is then transformed from the $\alpha \beta$-system to the $d q$-system by a Park transformation where usually the flux angle is used as the transformation angle $\theta_{s}$. The transformation angle $\theta_{s}$ is estimated from the current model by using the $d q$-currents and rotor speed $N_{r}$. In this way a flux-oriented system is obtained. For the DC-currents obtained after the transformations, usually a standard PIregulator together with some feed-forward terms is used. The output of the current regulator is the stator voltage space vector, expressed in the $d q$-system. The stator voltage space vector is then transformed back to the stationary three phase system using inverse Park and inverse Clarke transformations and the obtained phase voltages are used as reference for the PWM pulse generation. At the same time, the input and capacitor voltages are sensed for calculating 


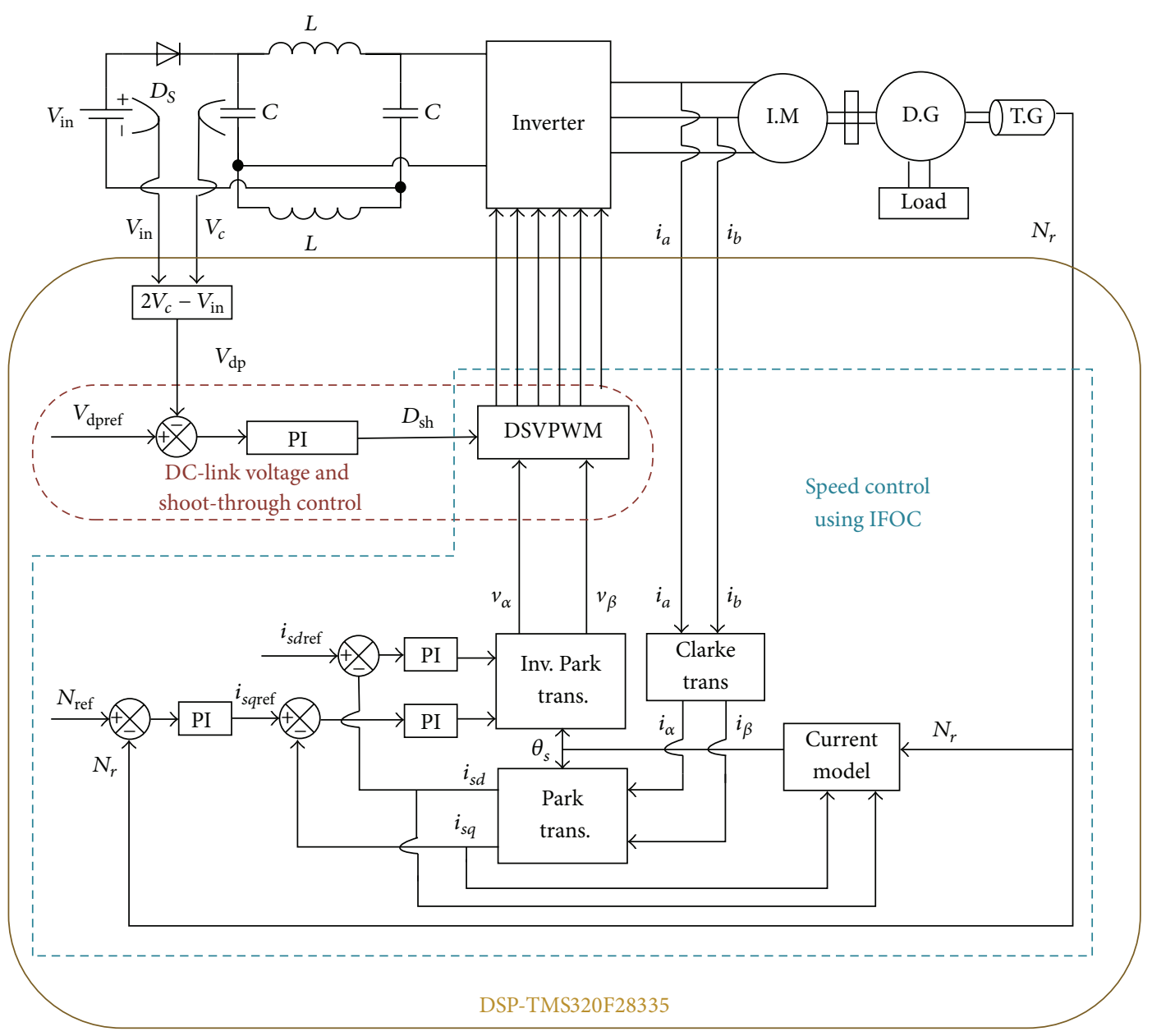

FIGURE 10: Schematic diagram of ZSI fed induction motor coupled with DC generator.

the DC-link voltage. This DC-link voltage is regulated using a PI controller, whose output is the shoot-through duty ratio $D_{\text {sh. }}$. The DSVPWM pulses with the shoot-through duty ratio $D_{\text {sh }}$ is realized using DSVPWM technique by programming the TI microcontroller. The flow chart for DSVPWM technique is shown in Figure 9.

The capacitor voltage $V_{c}$, input voltage $V_{\text {in }}$, motor line currents $i_{a}$ and $i_{b}$, and the rotor speed $N_{r}$ are sensed and given as feedback signals to the microcontroller shown in Figure 10. The CCS5.4 software with GUI composer from Texas Instruments provides integrated environment for the development of the target application. The IFOC with DSVPWM algorithm is programmed using CCS5.4 software and loaded into the microcontroller. The microcontroller executes the algorithm using the analog inputs to generate gating pulses for the inverter switches with required modulation and shootthrough time for speed and DC-link voltage control. The GUI composer scatter plot is utilized to monitor the realtime updating of the variables in the operation of the drive system. Some of the scatter plots obtained are shown as part of results in the latter part of this section. The DC-link voltage compensation has been successfully implemented.
To evaluate the performance of the ZSI based drive, a VSI based drive has also been implemented.

6.1. VSI Fed Induction Motor Drive. The VSI is connected to a $600 \mathrm{~V}$ DC source and feeds a $3.2 \mathrm{~kW}, 1500 \mathrm{rpm}$ three-phase squirrel induction motor. The motor is mechanically coupled to a $220 \mathrm{~V}, 3.2 \mathrm{~kW}$ seperately excited DC generator. The DC generator is loaded with incremental resistive loading. Two cases in which voltage drop takes place have been studied.

Case 1. The VSI fed drive is given a constant speed reference of $750 \mathrm{rpm}$. The torque, increased from no load to $30 \%$ of full load in three equal steps at $L_{1 i}(10 \%), L_{2 i}(20 \%)$, and $L_{3 i}$ (30\%) instants and decreased from $30 \%$ of full load to no load in three equal steps at $L_{1 d}(20 \%), L_{2 d}(10 \%)$, and $L_{3 d}$ (no load) instants by changing the loading on the coupled DC generator. The rotor speed is changing from 733 to $765 \mathrm{rpm}$ with load change. The rotor speed performance indices as peak over shoot, rise time, and setting time are $2 \%, 1 \mathrm{sec}$, and 2 secs, respectively. The response of rotor speed $N_{r}$ and input DC-link voltage $V_{\text {dp }}$ drop are shown in Figures 11(a) and 11(b). It can be observed that the IFOC results in speed control, but the DC-link voltage experiences voltage drop. 


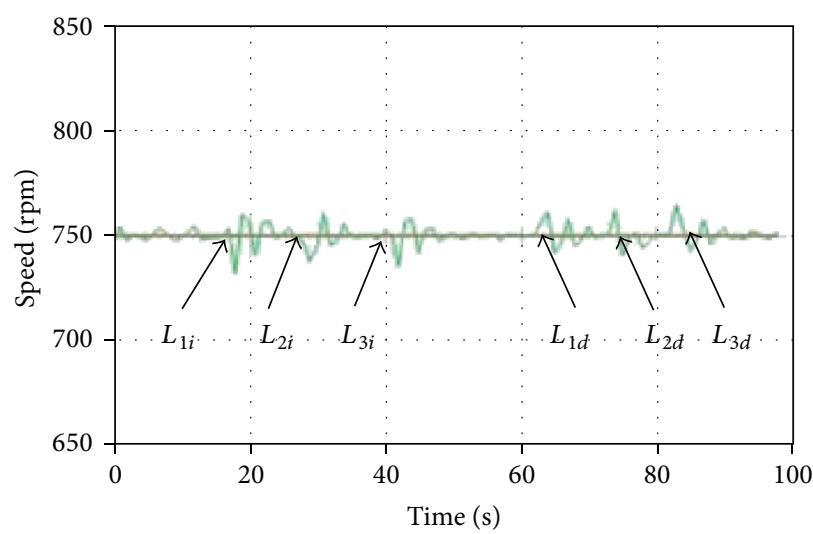

(a) Induction motor rotor speed

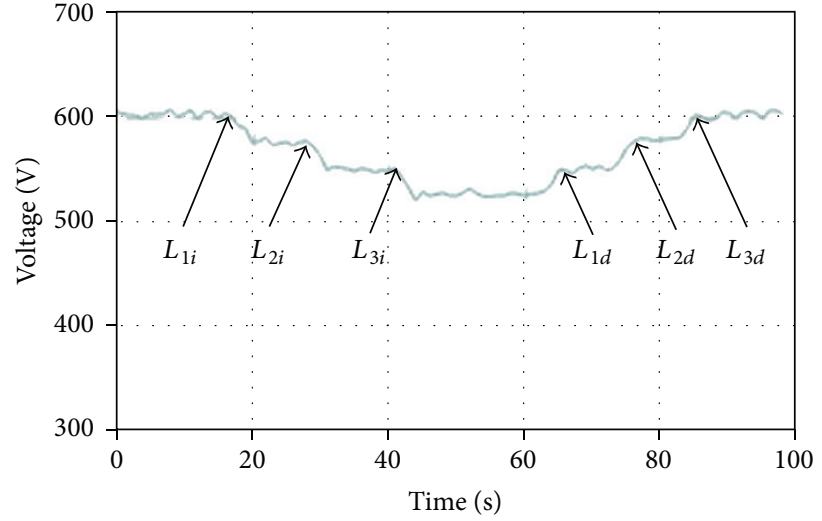

(b) DC-link voltage response

FIGURE 11: Response of VSI fed induction motor drive with load change.

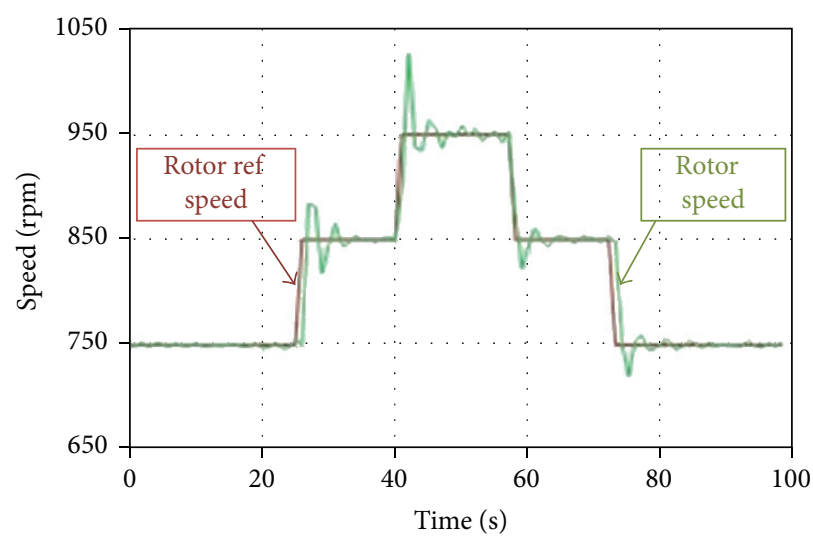

(a) Induction motor rotor speed

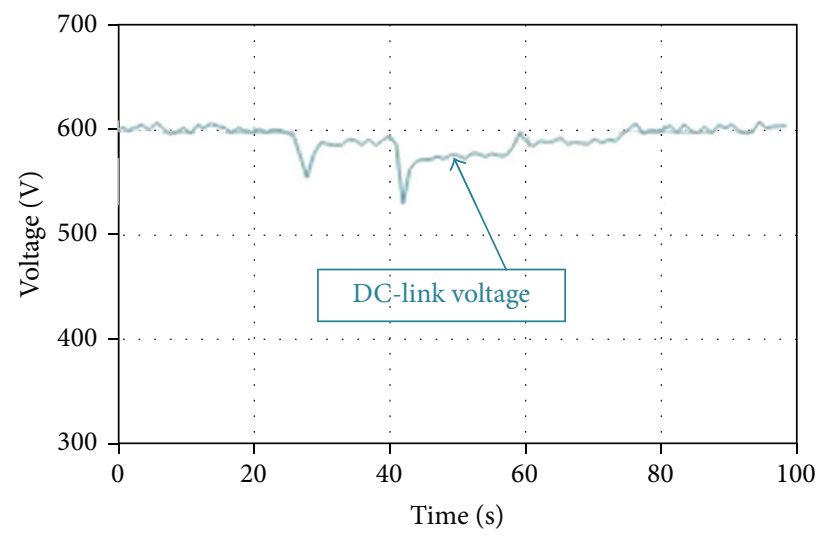

(b) DC-link voltage response

FIGURE 12: Response of VSI fed induction motor drive with speed change.

Case 2. The VSI fed drive is given four-step changes in speed reference from $750 \mathrm{rpm}$ to $850 \mathrm{rpm}$, to $950 \mathrm{rpm}$, to $850 \mathrm{rpm}$, and to $750 \mathrm{rpm}$ under loaded condition. The rotor speed performance indices as peak over shoot, rise time, and setting time are $10 \%, 2.5$ secs, and 5 secs, respectively. The motor speed follows the reference speed as shown in Figure 12(a) and the corresponding input DC-link voltage drop can be observed in Figure 12(b).

In both of the above cases of VSI fed drive, voltage drop remains uncompensated. The modulation index $m$ of VSI varies to maintain constant rated flux in the motor.

\subsection{ZSI Fed Induction Motor Drive with DSVPWM Technique.}

The ZSI is connected to a $400 \mathrm{~V}$ DC source and feeds the induction motor-DC generator set previously mentioned. The two cases studied in VSI drive are studied here for comparison.

Case 1. The ZSI fed drive, under constant speed reference $750 \mathrm{rpm}$ and varying load torque, not only maintains the speed but also compensates the DC-link voltage to $600 \mathrm{~V}$. The rotor speed is changing from 748 to $752 \mathrm{rpm}$ with load change. The rotor speed performance indices as peak over shoot, rise time, and setting time are $0.26 \%, 0.1$ secs, and 0.3 secs, respectively. Figures 13 (a) and 13(b) show the rotor speed $N_{r}$, DC-link voltage $V_{\mathrm{dp}}$, capacitor voltage $V_{c}$, and input voltage $V_{\text {in }}$ response.

Case 2. The speed reference of ZSI fed drive is changed in four steps as in the case of VSI under loading condition. The motor speed $N_{r}$ and the DC-link voltage $V_{\mathrm{dp}}$ are following the speed reference and $600 \mathrm{~V}$, respectively. Figures 14(a) and 14(b) show the rotor speed $N_{r}$ DC-link voltage $V_{\mathrm{dp}}$, capacitor voltage $V_{c}$, and input voltage $V_{\text {in }}$ response. The rotor speed performance indices as peak over shoot, rise time, and setting time are $2 \%, 1 \mathrm{sec}$, and $1.5 \mathrm{secs}$, respectively. The above observations from VSI and ZSI drives have been tabulated in Tables 4 and 5.

In both of the above cases of ZSI fed drive, the DClink voltage is compensated owing to the shoot-through generation by DSVPWM technique used. Based on Table 4, Figure 15 shows the variation in DC-link voltage and modulation index in VSI and ZSI fed drives under constant speed and 


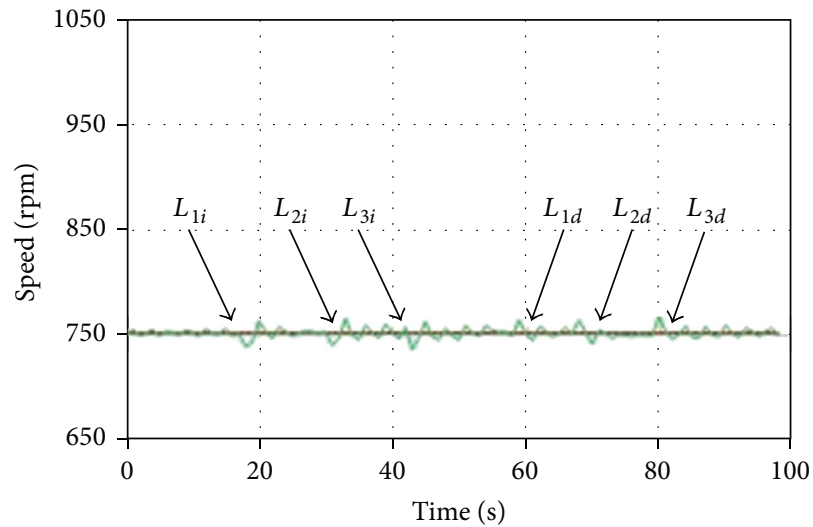

(a) Induction motor rotor speed

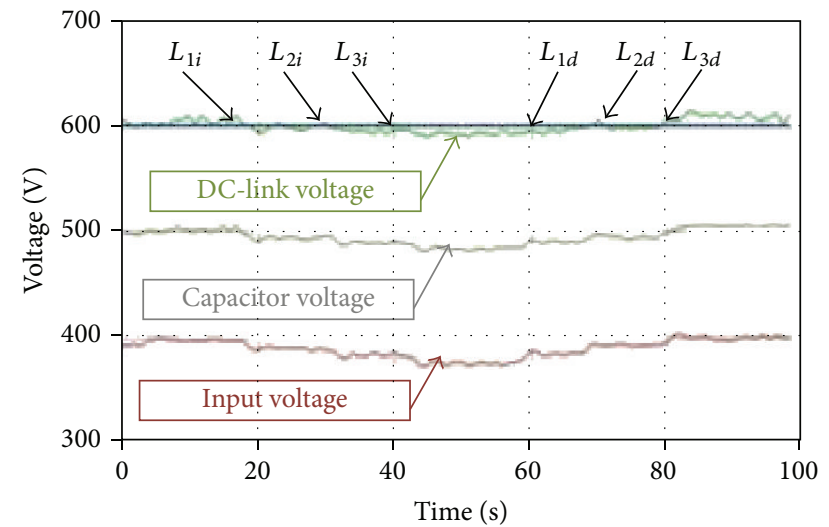

(b) DC-link voltage response

FIGURE 13: Response of ZSI fed induction motor drive with load change.

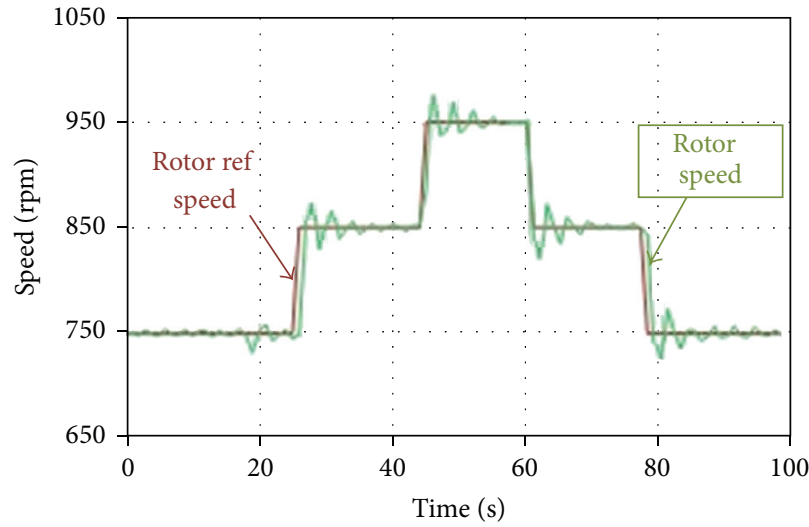

(a) Induction motor rotor speed

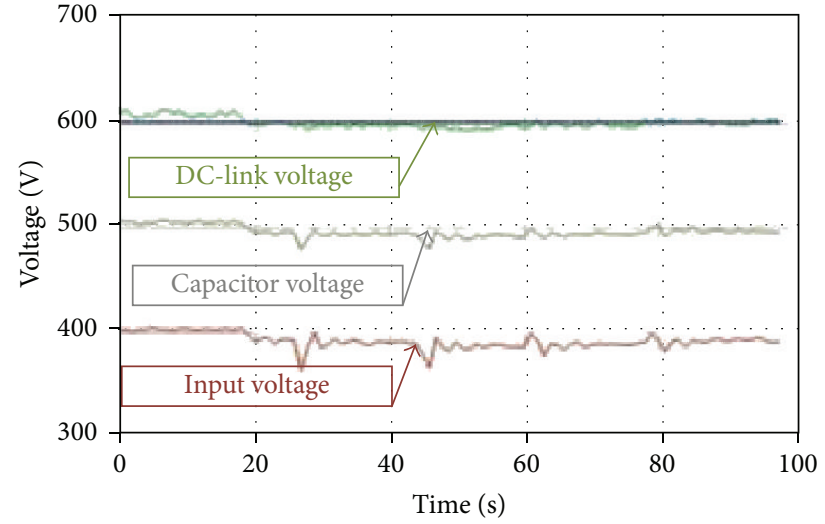

(b) DC-link voltage response

FIGURE 14: Response of ZSI fed induction motor drive with speed change.

TABLE 4: Hardware results comparison of VSI and ZSI drives with load-torque step change from no load to $30 \%$ load as reference speed of $750 \mathrm{rpm}$ at $600 \mathrm{~V}$ DC-link voltage.

\begin{tabular}{|c|c|c|c|c|c|c|c|}
\hline \multirow{3}{*}{ Load torque } & \multicolumn{3}{|c|}{ SVPWM-VSI drive } & \multicolumn{4}{|c|}{ DSVPWM-ZSI drive } \\
\hline & \multicolumn{2}{|c|}{ Overshoot of speed } & \multirow{2}{*}{$\begin{array}{c}\text { Voltage (volts) } \\
\text { DC-link }\end{array}$} & \multicolumn{2}{|c|}{ Speed peak (rpm) } & \multicolumn{2}{|c|}{ Voltage (volts) } \\
\hline & Min. & Max. & & Min. & Max. & Input & DC-link \\
\hline $10 \%$ & $98 \%$ & $101 \%$ & $95.83 \%$ & $99.73 \%$ & $100.266 \%$ & $97.5 \%$ & $100 \%$ \\
\hline $20 \%$ & $97 \%$ & $102 \%$ & $91.67 \%$ & $99.8 \%$ & $100.266 \%$ & $95 \%$ & $100 \%$ \\
\hline $30 \%$ & $98 \%$ & $101 \%$ & $86.67 \%$ & $99.73 \%$ & $100.266 \%$ & $92.5 \%$ & $100 \%$ \\
\hline
\end{tabular}

TABLE 5: Hardware results comparison of VSI and ZSI drives with speed step change at $600 \mathrm{~V}$ DC-link voltage.

\begin{tabular}{|c|c|c|c|c|c|c|c|}
\hline \multirow{3}{*}{ Speed change } & \multicolumn{3}{|c|}{ SVPWM-VSI drive } & \multicolumn{4}{|c|}{ DSVPWM-ZSI drive } \\
\hline & \multicolumn{2}{|c|}{ Overshoot of speed } & \multirow{2}{*}{$\begin{array}{c}\text { Voltage (volts) } \\
\text { DC-link }\end{array}$} & \multicolumn{2}{|c|}{ Speed peak (rpm) } & \multicolumn{2}{|c|}{ Voltage (volts) } \\
\hline & Min. & Max. & & Min. & Max. & Input & DC-link \\
\hline $750-850 \mathrm{rpm}$ & $96.48 \%$ & $104.7 \%$ & $96.67 \%$ & $99.42 \%$ & $100.23 \%$ & $97.5 \%$ & $100 \%$ \\
\hline $850-950 \mathrm{rpm}$ & $98.95 \%$ & $109.47 \%$ & $93.34 \%$ & $99.48 \%$ & $100.63 \%$ & $95 \%$ & $100 \%$ \\
\hline
\end{tabular}




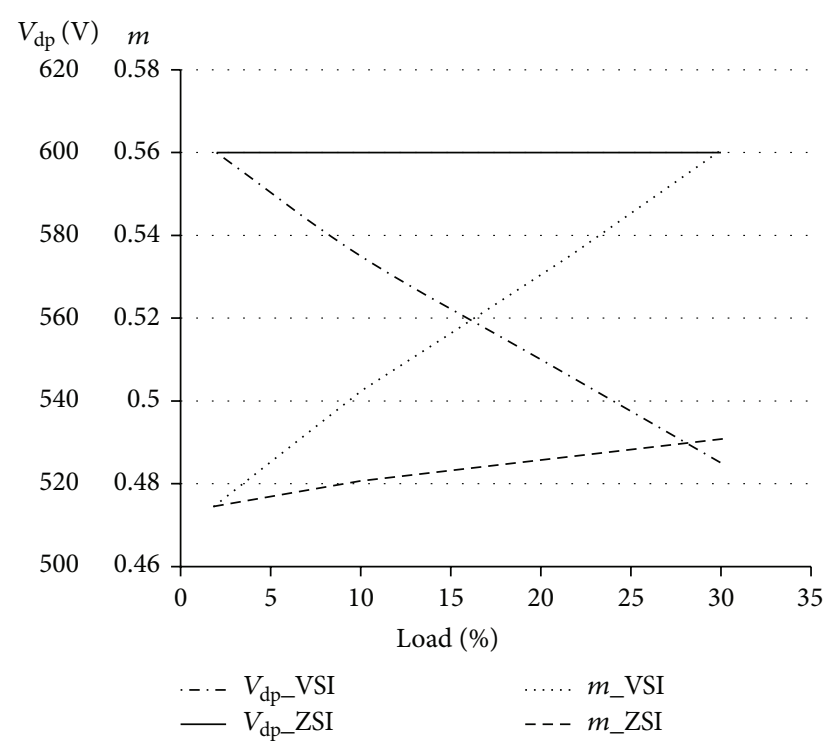

FIGURE 15: Response of DC-link/capacitor voltage and modulation index in VSI and ZSI with load change.

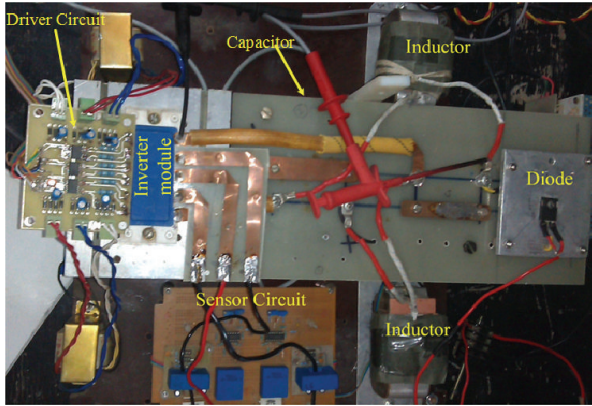

(a)

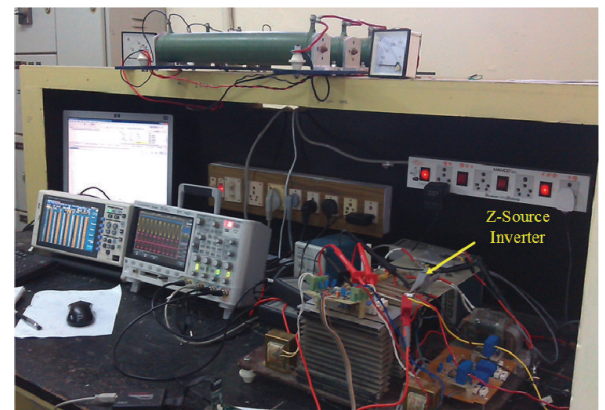

(b)

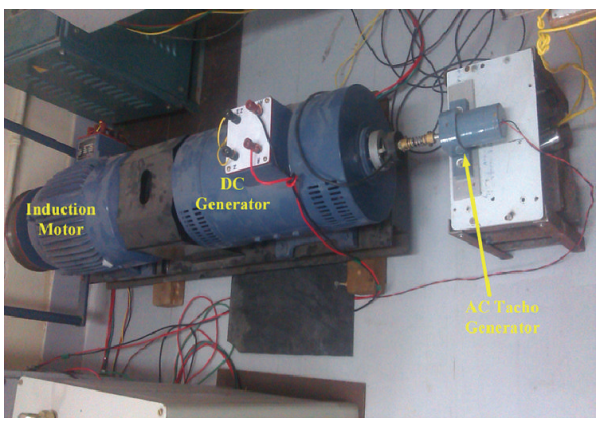

(c)

FIGURE 16: Experimental setup.

variable load torque mode. The drop in DC-link voltage of VSI on increased loading is too large and in ZSI the DC-link voltage is maintained constant. Hence, modulation index " $m$ " of the VSI increases steeply compared to that in the ZSI fed drive. This is because the Z-network in ZSI fed drive provides the boost to the DC-link voltage, thereby causing less rise in modulation index " $m$."

Figure 16(a) shows the Z-network elements inductor and capacitor and IPM inverter module (BSM50GD120DN2E3226) with driver (ADUM4332) circuit which are the main components in Z-source inverter. Figure 16(b) shows the total setup of the Z-source inverter. Figure 16 (c) shows $3.5 \mathrm{~kW}$ motorgeneration load setup for Z-source inverter and the speed of the motor is measured through the AC-tachogenerator. The speed sensor output is sine wave and it is converted into pulses using a zero crossing detector circuit. The pulses are fed through the capture module of the DSP for speed sensing. 


\section{Conclusion}

This paper presents the DSVPWM boost control scheme for the DC-link voltage control of Z-source inverter. The proposed DSVPWM based Z-source inverter is capable of compensating voltage drop by generating required shootthrough. A prototype of a $3.5 \mathrm{~kW}$ VSI and ZSI fed induction motor drives are designed and implemented with a DSP controller based on the TMS320F28335 evaluation board. The following observations have been made. For load changes, the DSVPWM based ZSI drive shows reduced speed overshoot, rise time, and settling time apart from eliminating the DClink voltage drops as compared to a VSI fed drive. For speed changes, the proposed technique shows reduced speed dips apart from maintaining the DC-link voltage stably. This shows that the DSVPWM with ZSI drive has better performance than the VSI drive. This technique greatly improves the voltage boost and utilizes the DC-link voltage effectively than classical SBC method.

\section{Appendix}

Consider the following:

The maximum output power $=3.5 \mathrm{~kW}$.

The input DC source voltage $=400 \mathrm{~V}$.

The peak DC-link voltage $=600 \mathrm{~V}$.

Average inductor current is

$$
\bar{I}_{L}=\frac{1500}{400}=8.75 \mathrm{~A} .
$$

Max. inductor current $\widehat{I}_{L}=\bar{I}_{L}+30 \% I_{L}=11.375 \mathrm{~A}$. Min. inductor current $\check{I}_{L}=\bar{I}_{L}-30 \% I_{L}=6.125 \mathrm{~A}$. $\Delta I=\widehat{I}_{L}-\check{I}_{L}=5.25 \mathrm{~A}$.

From (7), boosting factor is

$$
B=\frac{V_{\mathrm{dp}}}{V_{\text {in }}}=1.5 .
$$

From (9), shoot-through duty ratio $D_{\text {sh }}=0.1667$. Switching frequency is $f_{S}=1 / T=10 \mathrm{kHz}$.

Shoot-through time $T_{\mathrm{sh}}=D_{\mathrm{sh}} * T=16.67 \mu \mathrm{S}$. From (10), capacitor voltage is

$$
V_{c}=\frac{(B+1) V_{\text {in }}}{2}=500 \mathrm{~V}
$$

From (12), inductor value is

$$
L=\frac{500 * 16.67 \mu \mathrm{s}}{5.25}=1.6 \mathrm{mH} .
$$

Capacitor voltage ripple $\left(\Delta V_{c}\right)$ is $1 \%$.

From (13), capacitor value is

$$
C=\frac{5.25 * 16.67 \mu \mathrm{s}}{500 * 0.01}=29.1 \mu \mathrm{F} .
$$

\section{Conflict of Interests}

The authors declare that there is no conflict of interests regarding the publication of this paper.

\section{References}

[1] C. C. Chan, "The state of the art of electric and hybrid vehicles," Proceedings of the IEEE, vol. 90, no. 2, pp. 247-275, 2002.

[2] T. Shekhar and J. Shrivastava, "Energy management \& control performance analysis of hybrid electric vehicle," Energy, vol. 3, no. 3, pp. 58-62, 2015.

[3] N. Mohan, T. M. Undeland, and W. P. Robbins, Power Electronics: Converters, Applications, and Design, Wiley, New Delhi, India, 2007.

[4] Y.-H. Hung and C.-H. Wu, "A combined optimal sizing and energy management approach for hybrid in-wheel motors of EV s," Applied Energy, vol. 139, pp. 260-271, 2015.

[5] M. Morawiec, "Sensorless control of induction machine supplied by current source inverter," Asian Journal of Control, 2015.

[6] M. Sreejeth, M. Singh, and P. Kumar, "Particle swarm optimisation in efficiency improvement of vector controlled surface mounted permanent magnet synchronous motor drive," IET Power Electronics, vol. 8, no. 5, pp. 760-769, 2015.

[7] P. Vas, Sensorless Vector and Direct Torque Control, Oxford University Press, New York, NY, USA, 1998.

[8] Y. Liu, B. Ge, H. Abu-Rub, and F. Z. Peng, "Overview of space vector modulations for three-phase Z-Source/quasi-z-source inverters," IEEE Transactions on Power Electronics, vol. 29, no. 4, pp. 2098-2108, 2014.

[9] J. Liu, J. Hu, and L. Xu, "Dynamic modeling and analysis of $\mathrm{Z}$ source converter-derivation of AC small signal model and design-oriented analysis," IEEE Transactions on Power Electronics, vol. 22, no. 5, pp. 1786-1796, 2007.

[10] Y. P. Siwakoti, F. Z. Peng, F. Blaabjerg, P. C. Loh, G. E. Town, and S. Yang, "Impedance-source networks for electric power conversion part II: review of control and modulation techniques," IEEE Transactions on Power Electronics, vol. 30, no. 4, pp. 1887-1906, 2015.

[11] C. J. Gajanayake, D. M. Vilathgamuwa, and P. C. Loh, "Smallsignal and signal-flow-graph modeling of switched z-source impedance network," IEEE Power Electronics Letters, vol. 3, no. 3, pp. 111-116, 2005.

[12] Z. Rymarski and K. Bernacki, "Influence of Z-Source output impedance on dynamic properties of single-phase voltage source inverters for uninterrupted power supply," IET Power Electronics, vol. 7, no. 8, pp. 1978-1988, 2014.

[13] P. C. Loh, D. M. Vilathgamuwa, Y. S. Lai, G. T. Chua, and Y. Li, "Pulse-width modulation of Z-source inverters," IEEE Transactions on Power Electronics, vol. 20, no. 6, pp. 1346-1355, 2005.

[14] Y. Tang, S. Xie, and J. Ding, "Pulsewidth modulation of Zsource inverters with minimum inductor current ripple," IEEE Transactions on Industrial Electronics, vol. 61, no. 1, pp. 98-106, 2014.

[15] F. Z. Peng, “Z-source inverter," IEEE Transactions on Industry Applications, vol. 39, no. 2, pp. 504-510, 2003.

[16] M. Hanif, M. Basu, and K. Gaughan, "Understanding the operation of a Z-source inverter for photovoltaic application with a design example," IET Power Electronics, vol. 4, no. 3, pp. 278-287, 2011. 
[17] R. K. Pongiannan, S. Paramasivam, and N. Yadaiah, "Dynamically reconfigurable pwm controller for three-phase voltagesource inverters," IEEE Transactions on Power Electronics, vol. 26, no. 6, pp. 1790-1799, 2011.

[18] M. Lakka, E. Koutroulis, and A. Dollas, "Development of an FPGA-based SPWM generator for high switching frequency DC/AC inverters," IEEE Transactions on Power Electronics, vol. 29, no. 1, pp. 356-365, 2014.

[19] Y. Liu, B. Ge, H. Abu-Rub, and F. Z. Peng, "Overview of space vector modulations for three-phase Z-Source/quasi-Z-source inverters," IEEE Transactions on Power Electronics, vol. 29, no. 4, pp. 2098-2108, 2014.

[20] A. Akkarapaka and D. Singh, "The IFOC based speed control of induction motor fed by a high performance Z-source inverter," in Proceedings of the International Conference on Renewable Energy Research and Application (ICRERA '14), pp. 539-543, IEEE, Milwaukee, Wis, USA, October 2014.

[21] L. Amezquita-Brooks, J. Liceaga-Castro, and E. Liceaga-Castro, "Speed and position controllers using indirect field-oriented control: a classical control approach," IEEE Transactions on Industrial Electronics, vol. 61, no. 4, pp. 1928-1943, 2014. 

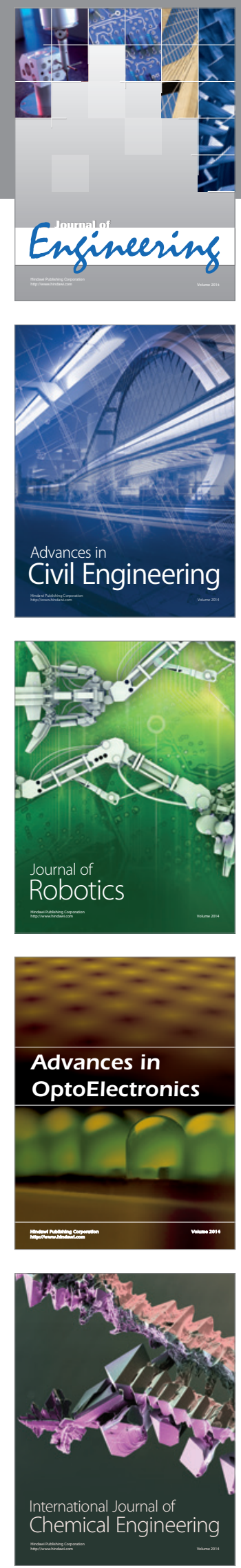

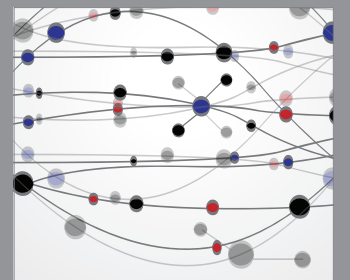

The Scientific World Journal
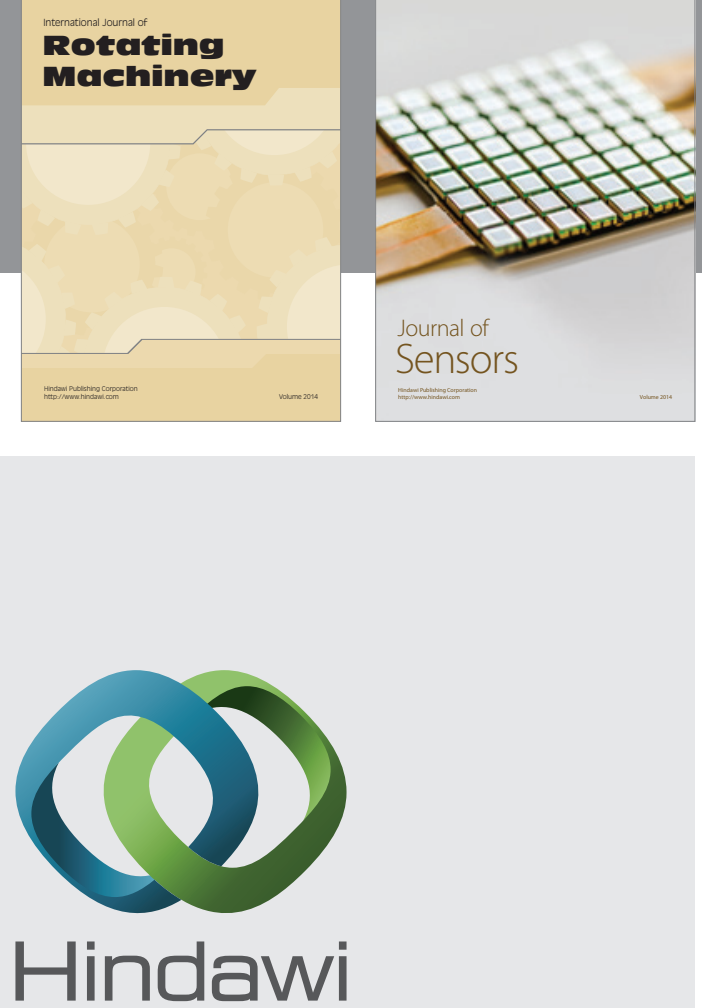

Submit your manuscripts at http://www.hindawi.com
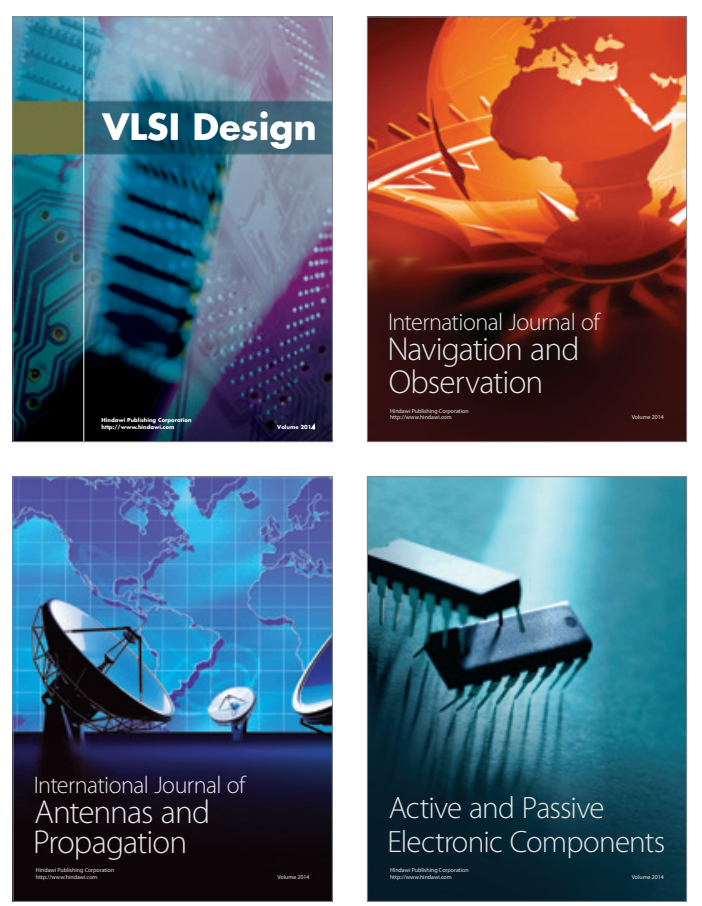
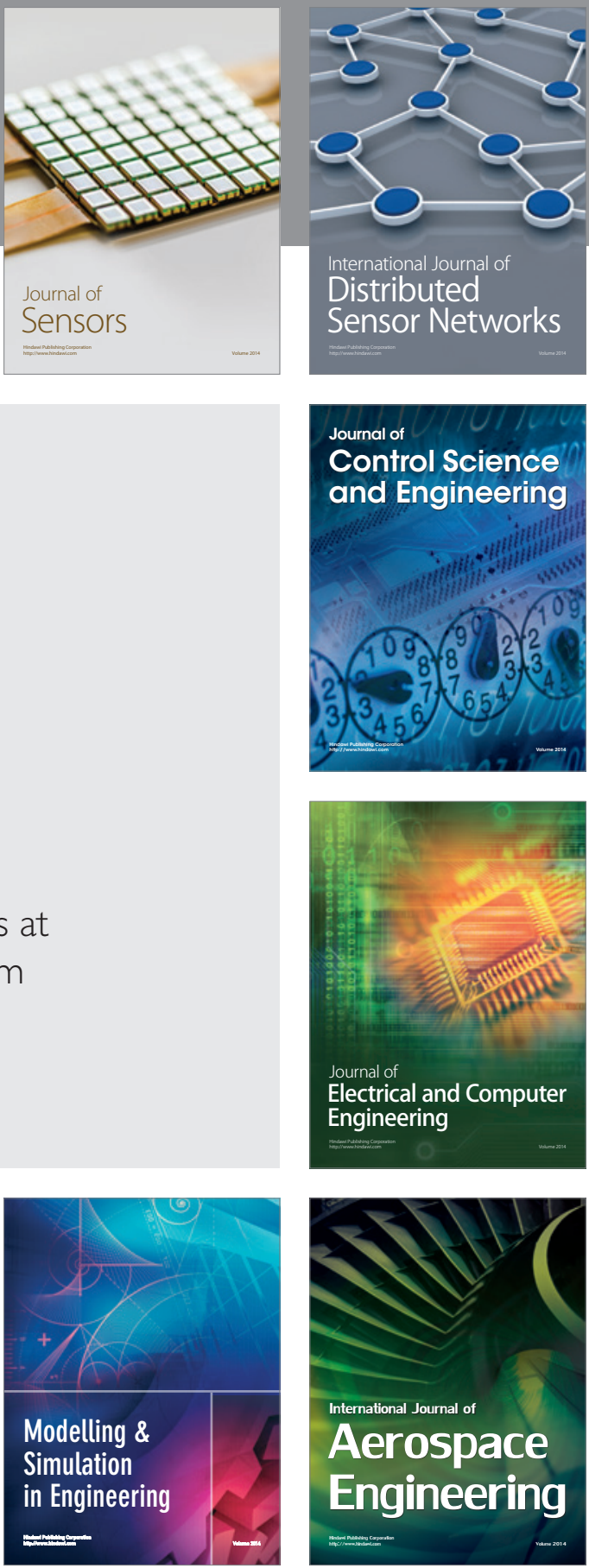

Journal of

Control Science

and Engineering
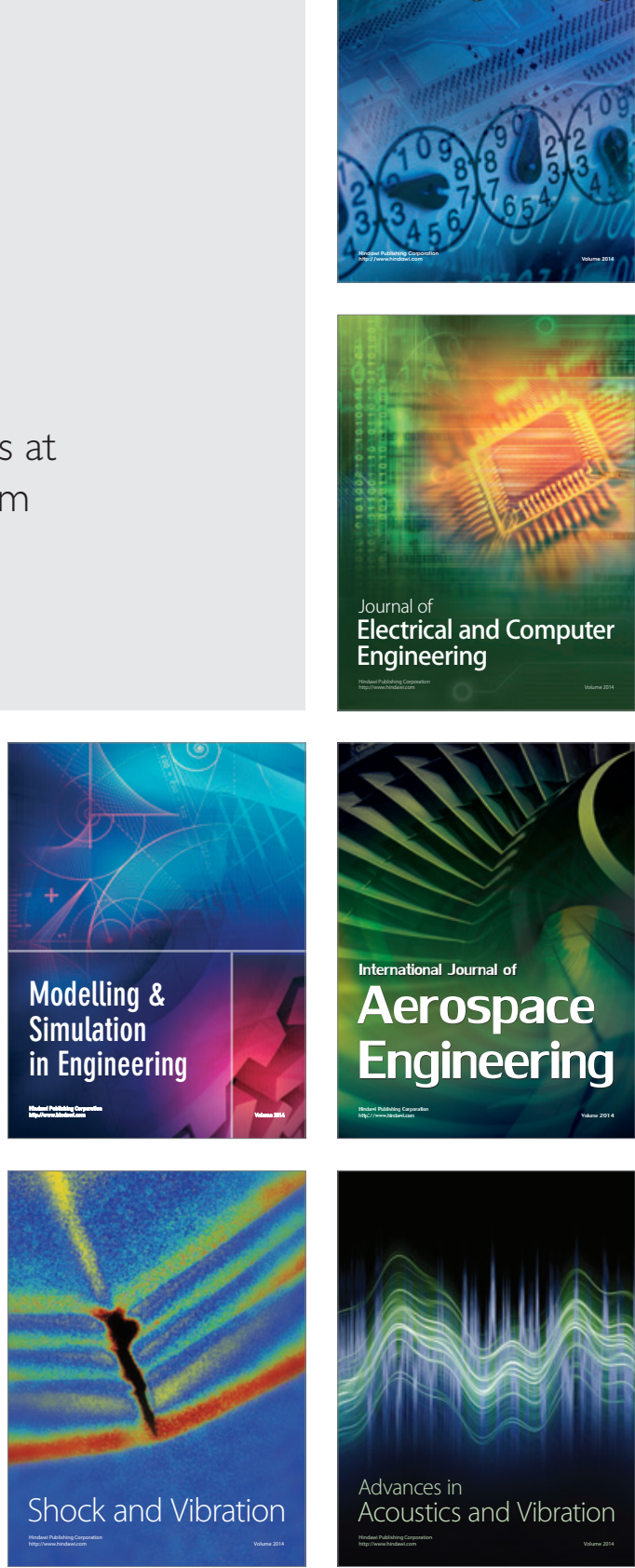